\title{
Luminance summation-contrast reduction as a basis for certain forward and backward masking effects'
}

\author{
Charles W. Eriksen and Joseph S. Lappin \\ UNIVERSITY OF ILLINOIS
}

\begin{abstract}
The forced-choice recognition of forms presented at brief durations in a tachistoscope was impaired when a second field luminance occurred concurrently with the form presentation or at brief intervals before or after. The results support the temporal luminance summation hypothesis and its bi-directionality in time.

\section{Problem}

Eriksen \& Hoffman (1963) have advanced a temporal luminance summation-contrast reduction hypothesis to account for certain cases of backward and foreward masking in vision. Due to the characteristic of the visual system to sum luminances over time intervals of nearly $100 \mathrm{~ms}$., presentation of an illuminated field at short intervals prior to or following a field containing a form or a display, will have the effect of adding equal luminance to both the figure and ground of the display. This results in reduced figure-ground contrast with resulting impaired recognition of the display. Considerable evidence has supported the luminance summation hypothesis (Eriksen \& Steffy, 1964; Steffy \& Eriksen, 1965; Thompson, 1964).

Sperling (1963) has also reported that the presentation of a homogeneously illuminated (informationless) field at brief delays following a display impairs perception. He interprets the phenomenon in terms of an erasure process that wipes out the brief perceptual memory or storage of the display. He further uses this "erasure" concept in developing a more elaborate model of the perceptual system. Eriksen \& Steffy (1964) have pointed out the inappropriateness on logical as well as experimental grounds of the erasure concept, but if it should be found that a homogeneously illuminated field that precedes a figure or display by a brief interval has the same impairment on perception as when it follows, the invalidity of an erasure concept would be selfevident. One cannot erase that which is not yet present.

The purpose of this experiment was: (a) to verify Thompson's (1964) findings with different techniques and methodology; and (b) to determine whether the luminance summation effect was symetrical, e.g., that the perceptual masking effect of an illuminated field was essentially the same when it preceded the stimulus at brief intervals as when it followed it.

\section{Method}

By the use of a three field tachistoscope containing an adapting field (FA) and two stimulus fields (F I and F II), it is possible to demonstrate the luminance summation-contrast reduction effect in a straightforward manner. With the FA dark but containing a faintly lumi- nous fixation point, black forms on a white ground can be presented in F I with the return to FA. The exposure duration necessary for 80 to $85 \%$ correct forced-choice recognition of the forms can then be determined. By using differing degrees of gray papers in F II the luminance contributed by this field can be varied and the figure-ground contrast of the stimulus in F I can be varied by simultaneously presenting F II with the occurrence of F I. Since the luminance from F II passes directly to the eye, the effect of presenting F II simultaneously with F I is to add equal increments of luminance to the retinal areas receiving figure and ground stimulation from the stimulus in F I, thus varying the figure-ground contrast. The effect of the second field luminance can be assessed in the percentage reduction in forced-choice recognition accuracy of the F I stimulus. The temporal luminance summation effect and its bi-directionality can be assessed by flashing F II at measured time intervals before or after the stimulus in $\mathbf{F ~ I}$.

The stimulus forms were the letters A, T, and $U$. Over several practice sessions an exposure duration was determined for each $\mathrm{S}$ that yielded 80 or $85 \%$ correct forced-choice recognition. This base level was determined under the standard condition of a dark FA with glowing $\mathrm{X}$ fixation point and presentation of the letter in F I with immediate return to FA. Under this base level condition the letter mounted on a white ground had a reflected luminance of .009 apparent $\mathrm{ft}$ candles and the ground .200 apparent $\mathrm{ft}$ candles for a contrast ratio of 22:1. Two levels of luminance were employed in F II, .200 and .084 apparent $\mathrm{ft}$ candles. When the F II luminances were superimposed upon the stimulus presentation in $F \mathrm{I}$, they reduced the contrast ratio of the F I form to 1.9:1 for the higher F II luminance and 3.0:1 for the lower F II luminance value. The exposure durations for F I and F II were always identical with the values determined for $S$ during the base level sessions.

Experimental trials were obtained under two orders of the F I and F II stimulations at each of the two levels of F II luminance. For the be for eorder the F II stimulation terminated 100,50 , and $10 \mathrm{~ms}$. prior to onset of the stimulus in FI. In the a f ter order the F II occurred 10,50 , or $100 \mathrm{~ms}$. following termination of the F I stimulus. Also trials were obtained where the F I and F II stimuli occurred concurrently.

The Ss were four undergraduate students (two females) who were paid volunteers. Each $\mathrm{S}$ served 22 sessions, inclusive of the base level and practice sessions during 
which he made 50 judgments under each time interval under each of the two orders and two levels of F II luminance. Subjects were run in a counterbalanced order for the four experimental treatments.

\section{Resuits}

The number of correct recognitions were analyzed by a four-way analysis of variance (before and after order, time interval between F I and F II, luminance of F II, and Ss). The main effects for time intervals, F II luminance and the interaction between time intervals and F II luminance were all significant beyond the .01 level. The order of occurrence of F II either before or after F I was not significant $(F=0)$, a result to be expected if the luminance summation effect was bi-directional. None of the other interactions were significant and the main effect for Ss fell just short of significance at the .05 level.

In Fig. 1 recognition is plotted as a function of time interval separation of F I and F II for the before and after orders and the two F II luminances. Three conclusions are clearly evident in Fig. 1. First, the role of contrast reduction in recognition accuracy is appar-

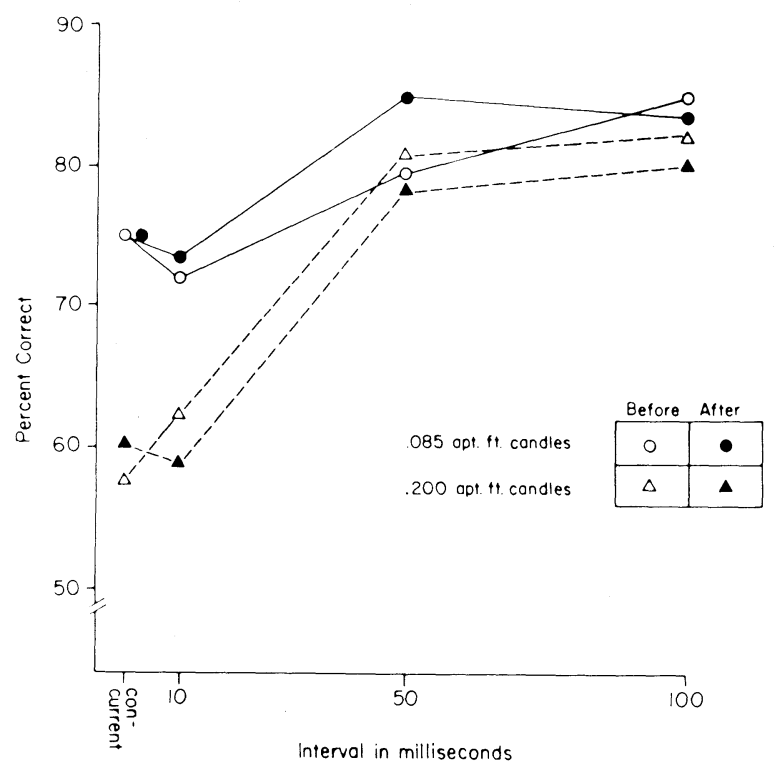

Fig. 1. Recognition accuracy as a function of time interval separation of F I and F II for the before and after orders and the two F II luminances. ent in that recognition is poorer when the .200 apparent $\mathrm{ft}$ candle $\mathrm{F}$ II luminance occurs concurrently with the F I stimulus than when the .084 apparent ft candle luminance occurs. Second, temporal luminance summation is demonstrated by the reduction in recognition accuracy when the $\mathrm{F}$ II masking luminance occurs as much as $50 \mathrm{~ms}$. after the termination of the F I stimulus or terminates as long as $50 \mathrm{~ms}$. before. Further this temporal luminance summation with resulting contrast reduction for the F I stimulus is directly proportional to the F II luminance. At time intervals of $10 \mathrm{~ms}$. or less between F I and F II, summation appears complete in terms of the recognition accuracy criterion. And lastly, temporal luminance summation is seen to be symetrical or bi-directional in time in that the functions obtained for the before and the after order of F II are apparently identical.

The present results support the previous studies, cited above, on the temporal luminance summation hypothesis and make increasingly clear that temporal luminance summation with resulting figure-ground contrast reduction is an explanatory process in certain cases of foreward and backward masking effects in vision. The bi-directionality for the summation confirms the previous finding of Eriksen and Hoffman (1963) and would seem to render Sperling's (1963) erasure concept completely inappropriate.

\section{References}

ERIKSEN, C. W., \& HOFFMAN, M. Form recognition at brief durations as a function of adapting field and interval between stimulations. J.exp. Psychol., 1963, $66,485-499$.

ERIKSEN, C. W., \& STEFFY, R. A. Short term memory and retroactive interference in visual perception. J. exp. Psychol., in press.

SPERLING, G. A model for visual memory tasks. Human Factors, 1963, 5, 19-31.

STEFFY, R. A., \& ERIKSEN, C. W. Short term perceptual recognition memory for tachistoscopically presented nonsense forms. J. exp. Psychol., in press.

THOMPSON, J. H. What happens to the stimulus in backward masking? Unpublished doctoral dissertation, Univer. of Illinois, 1964.

\section{Note}

1. This research was supported by grants USPH M-1206 and USPH Research Career award K6 MH-22014. 